\title{
Beyond words: Aesthetic knowledge and knowing in design
}

Article

Accepted Version

Ewenstein, B. and Whyte, J. (2007) Beyond words: Aesthetic knowledge and knowing in design. Organization Studies, 28 (5). pp. 689-708. ISSN 0170-8406 doi:

https://doi.org/10.1177/0170840607078080 Available at https://centaur.reading.ac.uk/11979/

It is advisable to refer to the publisher's version if you intend to cite from the work. See Guidance on citing.

To link to this article DOI: http://dx.doi.org/10.1177/0170840607078080

All outputs in CentAUR are protected by Intellectual Property Rights law, including copyright law. Copyright and IPR is retained by the creators or other copyright holders. Terms and conditions for use of this material are defined in the End User Agreement.

\section{www.reading.ac.uk/centaur}

\section{CentAUR}

Central Archive at the University of Reading

Reading's research outputs online 


\title{
Beyond words: Aesthetic knowledge and knowing in organizations
}

\author{
Boris Ewenstein and Jennifer Whyte
}

Please reference as:

Ewenstein, Boris and Whyte, Jennifer (2007) "Beyond words: aesthetic knowledge and knowing in organizations." Organization Studies 28(5): 689-708.

The final, definitive version of this paper has been published in Organization Studies, 28/05, May 2007 by SAGE Publications Ltd, All rights reserved. (C) This is the accepted version, posted by the second author on the University of Reading website under the terms of the contributor agreement. 


\section{Beyond words: Aesthetic knowledge and knowing in organizations}

\section{Abstract}

Aesthetic knowledge comes from practitioners understanding the look, feel, smell, taste and sound of things. It is vital to work in many organizational contexts. In this paper we explore aesthetic knowledge and knowing in organizations through detailed observation of design work in the architectural practice Edward Cullinan Architects. Through our research, we explore aesthetic knowledge in the context of architectural work, unpacking what it is, how it is generated, how it is applied in design projects, shared between practitioners and developed at the level of the organization. Our analysis suggests that aesthetic knowledge plays an important part in organizational practice, not only as the symbolic context for work, but as an integral part of the work that people do. It suggests that aesthetic reflexivity, which involves an opening up and questioning of what is known, is experienced as part of practice as well as a 'time out' from practice.

Keywords: organizational knowledge and knowing, aesthetic knowledge, aesthetic reflexivity, practice 
Aesthetic knowledge is embodied. It comes from practitioners understanding the look, feel, smell, taste and sound of things in organizational life. Management consultants, for instance, reflexively enact aesthetic knowledge when they employ PowerPoint to communicate a strategy and persuade a client to adopt it. Medical doctors enact aesthetic knowledge when they inspect a bruise or skin irritation. Engineers enact it when they interpret the component shapes in technical drawings. Aesthetic knowledge and knowing are vital to work in organizational contexts such as architectural practices, scientific laboratories, retail outlets, operating theatres, football clubs, airline cabins and orchestras.

Aesthetic knowledge is derived from the senses and particular situations and experiences. In our discussion, we distinguish two dimensions. The first is symbolic, consisting of knowledge in the form of signs and symbols. The second is experiential, consisting of feelings and embodied experiences that emerge through knowledge use. Hence, aesthetic knowledge is both something that actors and communities can come to possess as an identifiable style, and something that becomes manifest in their practice as a specific competency.

Aesthetic reflexivity involves an opening up and questioning of what is known. It provides the mechanism through which aesthetic knowledge is developed and applied by practitioners. In our discussion, we distinguish two modes that relate to the dimensions of aesthetic knowledge. The first consists of sensing, symbol processing (Lash and Urry 1994: 112), interpreting and 'thinking' with aesthetic knowledge. The second consists of reflex-like interaction with a changing material context. Hence, aesthetic reflexivity is something that actors and communities engage in both as a form of reflection and as a reflexive practice. 


\begin{tabular}{|c|c|c|}
\hline & $\begin{array}{l}\text { Aesthetic } \\
\text { knowledge }\end{array}$ & $\begin{array}{l}\text { Aesthetic } \\
\text { reflexivity }\end{array}$ \\
\hline Symbolic & $\begin{array}{l}\text { Aesthetic knowledge as } \\
\text { style, constituted in } \\
\text { semiological terms and } \\
\text { grounded in a specific } \\
\text { vocabulary and syntax; } \\
\text { includes expression } \\
\text { through non-verbal } \\
\text { signifiers, referents and } \\
\text { signs. }\end{array}$ & $\begin{array}{l}\text { Aesthetic reflexivity as } \\
\text { reflection, involves } \\
\text { sensing, symbol- } \\
\text { processing, interpreting, } \\
\text { intuiting and 'thinking' } \\
\text { with aesthetic } \\
\text { knowledge. }\end{array}$ \\
\hline Experiential & $\begin{array}{l}\text { Aesthetic knowledge as } \\
\text { competency, } \\
\text { constituted in } \\
\text { phenomenological } \\
\text { terms and involves } \\
\text { feeling, sensitivity and } \\
\text { corporeal experience. }\end{array}$ & $\begin{array}{l}\text { Aesthetic reflexivity as } \\
\text { practice, constitutes a } \\
\text { reflex-like interaction } \\
\text { with a changing material } \\
\text { context, informed by } \\
\text { aesthetic knowledge. }\end{array}$ \\
\hline
\end{tabular}

Table 1. Aesthetic knowledge and its enactment through reflexivity.

Through a detailed study of day-to-day work in an architectural design practice, Edward Cullinan Architects, we explored aesthetic knowledge and knowing in this organization. In this paper we link our analysis of aesthetic knowledge and aesthetic reflexivity, which is summarized in Table 1, with the lived experiences of the architects that we observed. We chart the nature of aesthetic knowledge in this context; exploring what it is, how it is generated, how it is applied in design projects, shared between practitioners and developed at the level of the organization.

The categories in Table 1 describe the symbolic and experiential dimensions of aesthetic knowledge in terms of style and competency, and the corresponding modes of aesthetic reflexivity in terms of reflection and practice. In our empirical work we identify and discuss the patterns through which practitioners activate their aesthetic knowledge that accumulates over time and apply it to a specific situation. This generates an aesthetic reflexive response that can relate to either the aesthetic 
knowledge or the aesthetic experience. Aesthetic reflexivity that is in response to experience is a real-time phenomenon and may lead to adjustments that affect the way aesthetic knowledge is applied, or to adjustments to the aesthetic knowledge that is stored and brought to a situation. The vignettes of practice that we describe illustrate what can be observed about these processes.

The analysis suggests that aesthetic knowledge plays an important part in organizational practice; not only as the symbolic context for work, but also as an integral part of the work that people do. It suggests that aesthetic reflexivity is experienced as part of practice as well as a 'time out' from practice so as to reflect (Antonacopoulou and Tsoukas 2002).

\section{Conceptual background}

Our work builds on and extends research relating to organizations and aesthetics (Gagliardi 1996; Dean et al. 1997; Strati 1999; Linstead and Hopfl 2000). In these debates, the aesthetic is understood more widely than obvious questions of beauty, art and appearance (Hancock and Tyler 2000). It is seen as based on sense experience, involving perception, imagination and intuition.

Such research indicates that organizations operate within an aesthetic context. Aesthetic knowledge is described as being about 'particular modes of expression like the mottoes and images of the organization, its layout and decorations / furnishings, its architectural appearance, and the way people dress' - in short, the symbolic dimension of organizational life (Strati 1990: 208, see also Strati 1996 and 1998).

However, recent studies indicate that aesthetic knowledge may also be directly involved in the work that people do. In research on retail services, the concept of aesthetic labour is used to discuss customer service. Aesthetic work is understood to Accepted version, final publication: http://oss.sagepub.com/cgi/content/abstract/28/5/689 
operate on and through the body (Witz et al. 2003). Such aesthetic labour has to do with beauty in the widest sense; being, looking, sounding and acting in a manner that is pleasing to the customer's senses. A study of customer service describes workers' 'aesthetic skills and competencies' (Nickson et al. 2001: 186), where these competencies refer to a feeling for style, appearance and customer experience. While this literature focuses on aesthetic knowledge and labour narrowly in terms of workers' self-presentation (i.e. language, dialect, dress code, manners, style and body shape; Thompson et al. 2001: 937), it draws attention to an experiential dimension to organizational life.

Hence, our conceptual model of aesthetic knowledge, outlined above in Table 1, has both symbolic and experiential dimensions. Where aesthetic knowledge is expressed through the fluency and literacy with signs, it is symbolic in nature. This symbolic dimension includes non-verbal systems of symbolization and aesthetic communication (Gagliardi 1996) such as visual and musical languages (Barthes 1977). Where aesthetic knowledge is expressed through feeling and corporeal experience, it is experiential in nature. We see this experiential dimension broadly. As well as including activities associated with consumption, such as customer service, it includes production activities in contexts such as design and engineering. These involve the faculty of feeling in which aesthetic knowledge resides (Bourdieu 1992); for example in the experienced flute-maker being able to judge the 'right feel' of a world-class flute in the making (Cook and Yanow 1993).

Our work also builds on and extends accounts of reflexivity within organizations (e.g. Antonacopoulou and Tsoukas 2002). Reflexivity involves a selfconscious reflection, monitoring and questioning of one's own behaviour and the behaviour of others (Mead 1934; Giddens 1991; Beck 1992). With the increased flow 
of people, goods and information, individuals construct their identities through personal preferences and lifestyle choices to a far greater degree than they would have in the past. Traditional social structures and institutions such as religion and family no longer provide taken-for-granted roles. Reflexivity describes the ability of individuals and communities to reflect knowingly upon the social conditions of their existence. It plays an increasingly vital role within contemporary organizations, as individuals and groups reflect on and question the nature of the organizations they have constructed and processes of organizing; while simultaneously constructing their identity through their membership and participation.

In organization studies, Gherardi (1999) builds on recent sociological work to understand such reflexivity as 'cognitive' and highlights another form. Aesthetic reflexivity has been described as a form of sensing and symbol processing (Lash and Urry 1994: 112). It is based on aesthetic knowledge. With an enhanced flow and accumulation of signs and symbols in contemporary society, individuals use their association with signs and symbols to signal individuality and self identity. Recent work has explored the role of reflexivity in sub-cultural environments (Ewenstein 2004), where aesthetic communication and knowledge of signs and symbols is particularly evident given the obvious interest in fashion, art, music, film, the role of lingo, gait, codes, etc. Such work draws particular attention to a symbolic mode of aesthetic reflexivity.

However, in professional knowledge work, reflection can be on the material context as well as the self. As skills are developed, the reasoned responses of a novice become replaced by the spontaneous and seemingly unmediated judgements, recognitions and skills of the expert (Schön 1983, 1985; Dreyfus and Dreyfus 2005). In design, for instance, 'a reflective "conversation with the situation” unfolds' (Schön 
1985: 26) as the experienced practitioner attentively evaluates a changing situation. This can be observed in both the normal and routine activities which fall within a practitioner's routinized responses; and also in unexpected situations that require 'thinking about what we are doing while we are doing it' (Schön 1985: 23). This literature draws attention to an experiential mode of aesthetic reflexivity.

Hence, our conceptual model of aesthetic reflexivity, outlined above in Table 1, has symbolic and experiential modes. If aesthetic reflexivity is enacted through reflection, it is symbolic in nature. This symbolic mode includes tacit understanding and 'pre-linguistic' forms of consciousness and cognition (Whitfield 2005); and the processing or interpreting of aesthetic symbols (Lash and Urry 1994). It proceeds through intuition or 'bodily sense' (Gendlin 1992). If aesthetic reflexivity is enacted through practice, it is experiential in nature. This experiential mode involves a reflective conversation with the situation (Schön 1985); or a form of productive inquiry (Cook and Brown 1999). It involves learning-in-organizing (Gherardi 1999) and judgement made in the midst of practice (Yanow and Tsoukas 2005), in experience that is direct and present-at-hand (Schutz 1967).

\section{Research methods}

Our case study involved detailed observational work in a London-based architectural practice, Edward Cullinan Architects. We see architectural design as particularly illustrative of aesthetic knowledge work in organizations, given the importance of visual expression, the emphasis on spatial experience and the historic connections between architecture and the practices of art. Therefore our study builds on a theoretical sample that is focused on the phenomenon at the heart of our research problem (Glaser and Strauss 1967; Silverman 2000, see also Denzin and Lincoln 1994).

Accepted version, final publication: http://oss.sagepub.com/cgi/content/abstract/28/5/689 
Within Edward Cullinan Architects, we followed design practice on a range of projects; observing and interviewing key members of staff, collecting secondary data and being involved in informal conversations regarding work. Contact with the firm was initiated by the second author, who had previously collaborated on research with Robin, a senior director of the firm. Both authors were involved in the research design and set-up meeting with the firm. After this, to minimize the disruption caused by a research presence, the first author acted as the main point of contact. He spent 130 hours (of 33 days) with the firm over a six month period in 2004. During the time spent with the practice there were thirty architectural designers working there, in a single studio.

Case study work with the firm involved visits to the sites under development; it involved client and design team meetings, and it involved sustained periods of time spent inside the firm. Informed by the work of Geertz (1973), Van Maanen (1975; 1979) and Rosen (1988), the participant observation was guided by a desire to understand activity in its everyday environment. An interest in local meanings and the in vivo conditions of life and work within a group led to a certain amount of direct involvement. The first author helped to prepare group lunches, went on a fieldtrip with the office to visit existing buildings designed by the firm; he drank tea with the group at $4 \mathrm{pm}$, shared photographs taken during the research process back with the practice for their use; he celebrated a leaving-do and played pool, was occasionally asked for his opinion on a design issue and even served as a model for a character in a design drawing.

Through such engagement we sought to develop an appreciation of the social context in which practice becomes meaningful, and understand some of the local norms and values that mediate design work. This in turn informed our analysis of Accepted version, final publication: http://oss.sagepub.com/cgi/content/abstract/28/5/689 
observations, interview accounts and documentary materials. Our analysis of aesthetic knowing draws on Strati's (2000) subjective-empathic approach, wherein a sense of local meanings supports the empathic understanding of practice. In this account, the researcher's own aesthetic impressions are also considered as a means of addressing aesthetic knowing in the organization.

In this paper, we focus on the efforts of a particular design team working intensively on a competition project to create a master-plan for a college complex over two days. For the most part, the collected data are based on the first author's observation of their work through a number of meetings and different instances of individual and collective work. These were recorded in photographs and written up as field-notes. The first author charted the types of visual materials used and distinguished the ways in which they were used. These materials includes in particular visual representations such as schematic drawings, sketches, sections, elevations, CAD images, plans and photographic and three-dimensional images. In extensive field-notes he noted what design situations actors tried to resolve and how projects were advanced through interactions between them and their interactions with representations.

The narrow focus of the empirical data described gives it focus and coherence. However, two methodological issues we encountered with this observational data were the difficulty of interpreting what had been observed, particularly in the context of the knowledge-intensive expert work we were studying; and the need to infer wider clarification processes from the fragmented interactions that are observable.

We took a number of steps to address these issues in our data analysis. Informed by the principles of grounded theory building (Glaser and Strauss 1967), the movement between data collection and data analysis was iterative rather than Accepted version, final publication: http://oss.sagepub.com/cgi/content/abstract/28/5/689 
sequential and involved a continual refinement of our interpretations. Though the phenomenon at the heart of our investigation was of limited duration, in ongoing field-work and through specific follow-up interviews, emerging ideas were explored in greater detail and recurrent themes were validated by participants. As much of the work that we observed was non-verbal, this allowed us to learn more about what we had witnessed and why this was meaningful.

The multiple modes that we had used for collecting data also allowed for comparative work during analysis. We set up a shared server space that contains all of the electronic files. We separately printed and analysed photographs, notes and transcripts, and met to discuss our differing interpretations of these many times in the process of formulating our argument, writing and revising this paper. Our aim was to make sense of design episodes in a holistic way that combined the exploration of field-notes, recorded meetings, corresponding photographs and documents. The different data were clustered around design episodes and recurrent themes were identified as we viewed, read and discussed the datasets. In our analysis, we coded for visual materials and practices through which knowledge was generated, clarified, exchanged and developed.

In joint data discussions, the first author brought a sociological interest to the material, which was shared by the second author but supplemented by knowledge of architectural design and construction. We sometimes disagreed about what had been observed and where possible we then went back to our source data. For example, when our interpretation of a transcript differed, we revisited the digital recording and listened to the audio file containing the quotation in the paper. Though not involved in direct observation of the competition project work, the second author had visited the practice on a number of occasions during the data collection phase, both before, Accepted version, final publication: http://oss.sagepub.com/cgi/content/abstract/28/5/689 
during and after the competition project described in the paper and was also involved in a number of the feedback sessions that we arranged with groups of architects interested in our work.

These feedback sessions were an important part of the analysis and validating process. This included informal reviews of findings and more formal presentations back to the practice. We hoped that the architects could benefit from this by providing an opportunity and context in which to be reflexive about intuitive practices such as sketching, which are often unquestioned and tacitly absorbed into day-to-day activities. These sessions were a context in which to find a language that connects with the concerns of practitioners, supports validation and supplements empirical detail. We have checked our interpretations and conclusions with participants through every draft of this paper. Though the architects initially noted the difficulty in making some of the academic perspectives connect to practice, they increasingly responded with interest to our work and have been a useful test-bed for the emerging ideas.

\section{Aesthetic knowledge and knowing in Edward Cullinan Architects}

The practice we study, Edward Cullinan Architects, is a major contributor to British architecture. It was founded as a cooperative by Edward Cullinan (who is known as Ted) in 1965. The foreword of the latest book on the practice starts: 'The work of Edward Cullinan Architects has never been fashionable' (Finch 2005: 6) and the practice is not closely aligned with fads and fashions within architecture. The work of the practice does, however, have a clear heritage in architectural thought in $20^{\text {th }}$ century Britain. Architects would recognize a 'Cullinan building', though this recognition may come from the spatial sensibilities embodied in it - the way the 
building is designed to be lived in rather than the way it looks. There are clear debts to the arts and crafts tradition, and in a 1986 speech Ted talks of his ambition to,

'belong to and prolong a great tradition in architecture; a tradition that is at least 120 years old, a tradition that concerns itself with particular conditions and particular situations; one that composes with asymmetry and balance; is open in form and is expressive, and through expressiveness is decorative; a tradition that uses industrial production in the services of particularity as opposed to using its methods as a guide to an aesthetic of sameness and repetition' (Cullinan 1995 [1986]: 143).

The practice has clear modernist sensibilities, and Ted worked for the key modernist architect, Denys Lasdun, before founding his own practice. Yet this is not the modernism of the 'International Style' popularised through a 1932 exhibition in New York, nor is it the modernism of architects that emigrated to the USA such as Gropius and Mies van der Rohe. Ted's modernism is a modernism that grew primarily in northern Europe. He takes inspiration from sources such as Mackintosh's houses in Glasgow, Lubetkin's penguin pool in London, Berlage's Amsterdam Stock Exchange, and Scharoun's Berlin Philharmonic - as well as the work of others further afield such as Gaudi in Spain and Frank Lloyd Wright in the USA (Cullinan, 1995 [1986]). The work of the practice can be understood in the context of this alternative tradition of modernism. It is described in articles in the architectural press, and in books about the practice (e.g. RIBA 1984, Powell 1995; Finch 2005). Recent projects by the firm include the conceptual design and detailed planning of visitors' centres; educational and health facilities; and housing-led mixed-use urban regeneration.

The practice operates within the context of a British architecture profession that is highly fragmented in terms of aesthetics. Different traditions of architecture, with their differing logics of practice, come into conflict and compete. Architectural knowledge is only partially institutionalized, documented and given. Those working Accepted version, final publication: http://oss.sagepub.com/cgi/content/abstract/28/5/689 
in practice share some common knowledge from their training, and this is refreshed and updated through profession-wide events and the circulation of architectural magazines. There are also some shared norms of professional practice, for example, architects are expected to know the RIBA (Royal Institute of British Architects) Plan of Work, which outlines the steps in the design process. However, there are also a number of schools of thought on aesthetic issues within both the profession and professional education, and these may be championed and highlighted within the architectural media. At the most superficial level, these lead to fads and fashions within architecture, for instance with particular buildings and practices being championed as deconstructivist or postmodern.

Education into the profession takes at least seven years, with the formal teaching based on the design review of architectural schemes by lecturers and visiting practitioners. Such training in higher education replaced (and to some extent continues to overlay) an apprenticeship model in which novices learn through apprenticeship to a master of the craft. However, the extra-ordinary length of architectural education in the UK is subject to scrutiny. Through their various histories, architecture schools have become associated with the proponents of particular styles of architecture and different logics of practice. In the UK, just under half of the 36 schools are associated with the fine arts faculty of the university. An equal number are associated with social sciences and the built environment more broadly. Four are treated as part of the engineering faculty. While students take taught courses in architectural theory, the history of western architecture, building materials, structures and services; it is project-based studio work that makes up the bulk of the training. Across these schools students are acquainted with shared ways of expressing their ideas visually through conventionalized symbols and signs, and they will have Accepted version, final publication: http://oss.sagepub.com/cgi/content/abstract/28/5/689 
tuned their sensitivities and feelings for spaces in the studio. However the nature of this mentored studio work means that the aesthetics that are learnt in school depend on the aesthetics of the school and in particular on the aesthetics of the tutors encountered. As studio work is usually assessed on paper, it may even be argued that stylistic fads and fashions are exaggerated in this context.

Before taking the final professional exams designers will normally - although this may well be about to change - have done three years of studio work in the school to get an architecture degree, a year in practice as a 'year out student', two further years in school to get a diploma, followed by at least one additional year of professional practice. During this year there is formal training in professional responsibilities and practice. Within architectural practices there are designers at various stages of their training to become architects, working as 'year out students' and post diploma architectural assistants; as well as fully qualified architects. There are also architects that have come through different education systems in various parts of the world.

Despite the high fragmentation of aesthetic knowledge within the profession, both nationally and internationally, the competition design work that we observed takes place within an organization that has a strong and shared aesthetic knowledge base. Architects working within Edward Cullinan Architects share an understanding of architecture as a process of place-making, with collective interest in the inhabitation and use of their buildings by people. We could observe these values through their expression in a concern for local communities and environments. The buildings that are produced by the practice are not intended to provide 'statement architecture' but well-crafted high-quality places for inhabitants to enjoy. As Robin told us:

Accepted version, final publication: http://oss.sagepub.com/cgi/content/abstract/28/5/689 
And I think that's what's special about what we do is that it is a combination of being interested in performance, not technology per se, but much more about how things are going to work in the real world [...]. And about sp-, real space, coherent spaces, spaces that are good to be in, whether they're external or internal and a very careful response to the context in which you sit something, where it sits - it doesn't necessarily mean that you're doing what went before, you know, you might be doing something quite different. And then a real interest in negotiating that, both amongst ourselves and as a design team, and with the public and of course a long standing interest in the environment.'

The concerns of the practice - in performance; space that is good to be in; the context in which buildings are situated; how designs are negotiated and how they impact the environment - find expression in a palette of forms and materials that has a degree of constancy across the projects of the firm. The practice's reputation is based on a language of architecture combining elements such as the courtyard, routes, thresholds, and landscapes and distinct geometrical units such as the cylinder or drum. Figure 1 gives some examples of spaces designed by Edward Cullinan Architects. Taken on a field visit with the practice, these snapshots show the main room and entrance of a private house designed in 1999, and the façade of a primary school designed to provide passive solar gain and classrooms at the scale of the child in 1987-1990. They demonstrate the distinctive palette of materials and spatial compositions, with brickwork and timber elements and double height space. An architectural critic writes that brickwork and timber elements, 'sticks and bricks', are of primary importance (Powell 1995: 12). This choice of materials presents a distinctive contrast between solid and heavy, on the one hand, and light and light-weight elements, on the other. Hence the critic notes 'the usual Cullinan contrast between solidity and lightness, structure and superstructure' and 'the contrast between brick and render, steel and glass' (Powell 1995: 25). 

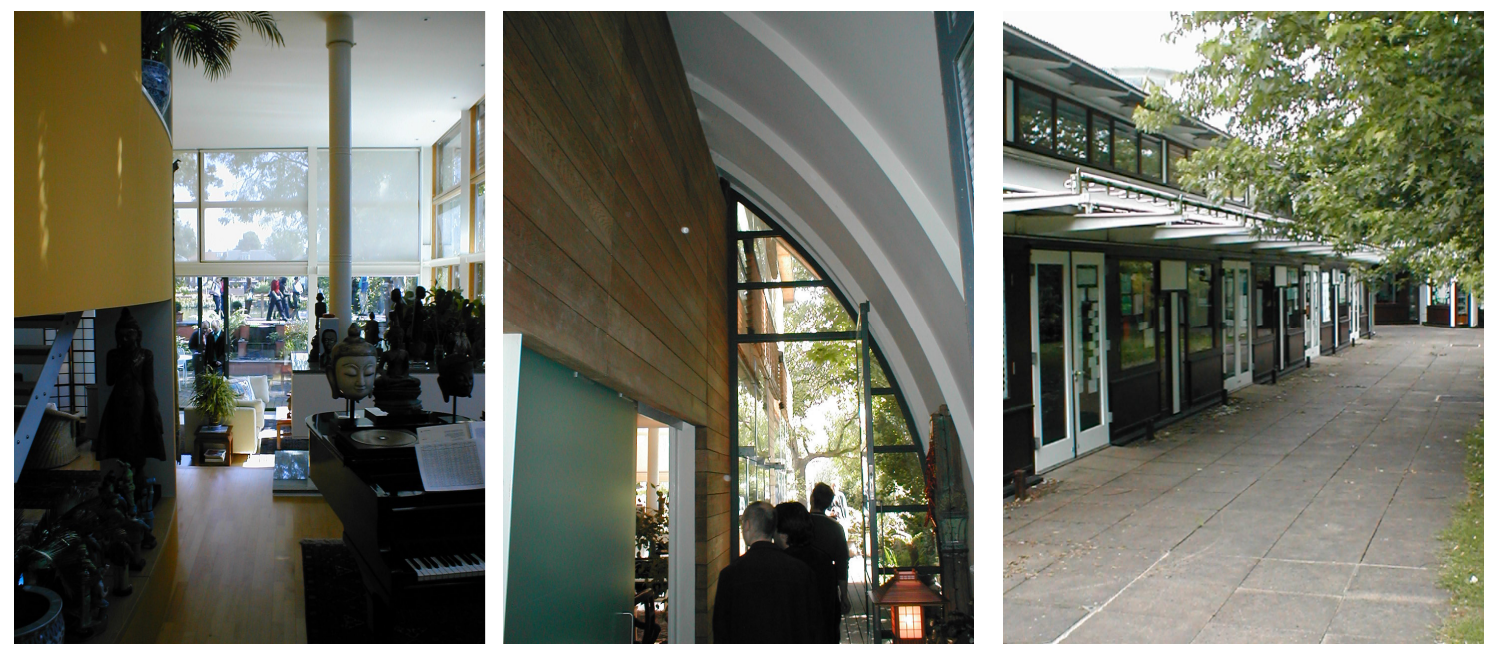

Figure 1. Snapshots of spaces designed by Edward Cullinan Architects.

Within the practice, aesthetic knowledge gravitates around the founder Ted Cullinan. Though this practice does not have the ethos of a 'signature' architectural practice, it is through the vision and leadership of Ted that their aesthetic knowledge is unified and made coherent. Discussing shared knowledge in the practice, Johnny notes,

'that plainly comes from Ted. The sharedness comes from the fact that $[\ldots]$ Ted's the person who is at the tiller, steering the projects in an early stage. Therefore what you'll see is a life through his eyes. [...] It's his view that will take precedent.'

In a separate interview, Robin echoes this evaluation. He says,

\footnotetext{
'there are certain very recognisable Cullinan buildings because Ted's been at it for a long time, and we buy into it. [...] But there is a collective, and people wouldn't be here if they didn't think it was roughly going in the right direction, and their wanting to be part of it and develop it.'
}

Edward Cullinan Architects is a particularly interesting contemporary organization. Rooted in the modernist sensibilities of the founder, the practice today Accepted version, final publication: http://oss.sagepub.com/cgi/content/abstract/28/5/689 
works for, and is itself part of, a society that is significantly different from that of its early years. During our time in the practice, there was considerable reflection on identity in light of this changing context. The aesthetic knowledge base of the practice continuously evolves as it is negotiated by members of the organization in the context of project-based design work. Design ideas are informed by documentations of previous projects within and beyond the practice, but the project team relies primarily on the people who worked on past projects and their accumulated experience. As one architect in Edward Cullinan Architects notes, 'knowledge comes from them, not paper'.

\section{Aesthetic reflexivity: reflection and practice in the competition design work}

This competition project that we observed - to develop a masterplan for a college complex - involves substantial work by Taylor and James, 'year-out students' in the practice and Emily, a post-diploma designer yet to qualify. It involves input from the other members of the team, Peter, a fully qualified architect, and Johnny, a fully qualified architect and senior director in the practice. We observed one meeting in which Peter and Johnny offer their feedback on the plans and sketches that Taylor, Emily and James have produced. In the meeting, aspects of the design to date are discussed, defined and critically evaluated.

At one point, Johnny begins to draw on a sketch central to the project. As he articulates his ideas on how the areas to either side of an arc-like path are to be used and integrated, a number of significant processes appear to unfold. The sketch is used to illustrate Johnny's idea; however, it is also changed and developed as the idea is being articulated and developed. What is observed is not so much fully formed 
knowledge being externalized through representation, but a conversation between the designer and the drawing in which knowledge emerges in action. Figure 2 shows Johnny marking lines onto the sketch, which represents the emerging concept for the college campus and a sports field, separated by a curvilinear path.

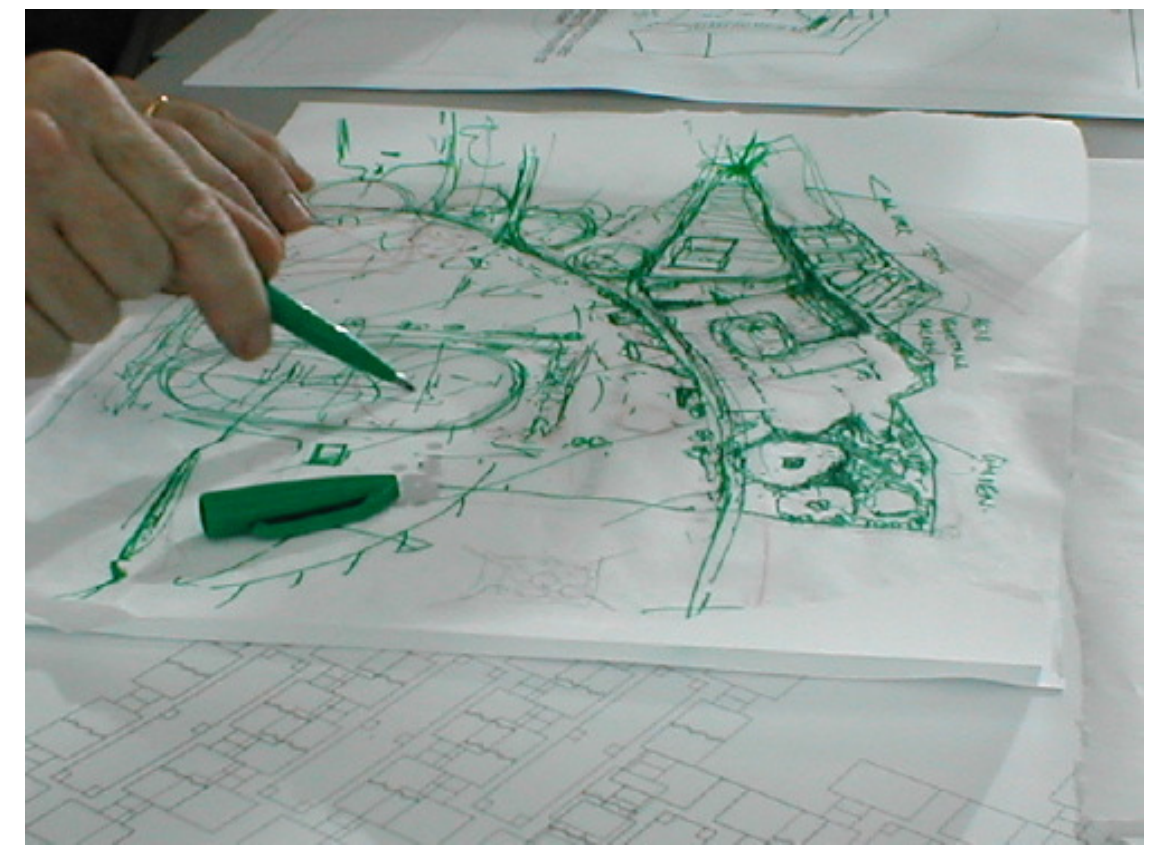

Figure 2. Johnny explaining, developing and sketching his ideas on how to integrate the campus building, right, with the park areas on the left side of the curved path.

Johnny's feedback and avid sketching are part of a reflex-like interaction with a changing material context, and they are informed by aesthetic knowledge. Recalling the meeting we observed, Johnny states:

[T]his was happening away from me. I was coming and seeing it for the first time and trying to give it a proper critique, which was, 'Ok, I haven't seen any of this, I don't know what you're doing. Here's my first take on it'. And I was using the drawing to say, 'Well, have you thought about that?' And it was maybe reacting to things, to lines that weren't [original Accepted version, final publication: http://oss.sagepub.com/cgi/content/abstract/28/5/689 
emphasis] there. And so I'm testing it by saying, 'Well, none of these lines are here, what happens if you put them on'?

Johnny is conducting a kind of inquiry. In the follow-up focus group discussion, he describes this process as 'inquiring of the geometry'. The relation between shapes and spaces was explored, at once sketching on the page and drawing on previous experience and acquired expertise.

It was this expertise and experience that Emily was interested in. As Johnny communicated both visually and verbally, Emily was interpreting, sensing and visualizing his suggestions and modes of reasoning.

Boris: Emily, what was your reaction to what Johnny was doing? To Johnny's sketching and explaining? What sense did you make of it all?

Emily: I guess I was interested in going back to his experience, to try and learn from what his experience was and why he was making these suggestions, maybe. And trying to visualize what he was explaining [emphasis added].

What is extraordinary about the observed patterns of interaction between the participants in the meeting is the degree to which they are conflict free and about mentoring and assistance. Both practitioners were involved in different forms of aesthetic reflexivity in this encounter. They manifest different modes of enacting aesthetic knowledge which are both central to their professional activity. Johnny was involved in a form of aesthetic reflexivity that resembles reflexivity as practice (see Table 1). Meanwhile, Emily was sensing, symbol-processing, interpreting, intuiting and 'thinking' with aesthetic knowledge. She was 'trying to visualize what he was explaining'. Her way of appreciating Johnny's feedback and assistance was in terms of aesthetic reflection (see Table 1). 
These processes of generating and applying aesthetic knowledge through reflexivity appear to have the characteristics of learning processes. As part of this interaction, the aesthetic knowledge embodied by Johnny is shared with Emily. As a senior representative of the aesthetic knowledge base of Edward Cullinan Architects, Johnny transmits some of this knowledge to more recent members of the practice through coaching on projects. It is through such processes and adjustments that aesthetic knowledge - be it a distinctive choice of materials or a more general way of approaching a design problem - is shared and thereby developed at the organizational level.

We observe how aesthetic reflexivity forms a part of practice. In their prior work Taylor, Emily and James had been exploring the properties of college environments that involve state of the art learning technology and flexible instruction spaces. They have considered the integration of the site with the wider surroundings; and experimented with in situ features such as a stream running through the site. Emily states in the meeting that, 'The site has a stream. I'm not sure how we use that.' To this, Peter replies with the suggestion to retain and integrate the stream actively into the design through the concept of recycling, which is directly connected to the project - a college in which environmental technology and material lifecycles are being taught. Here Peter is drawing on the aesthetic base of the firm, where the particularities of a site are active in generating the aesthetic qualities of the scheme. These aesthetic considerations are dealt with in a way that is integrated with the practical and functional.

In another design episode Taylor points to a drawing which is a developed version of an original sketch. The episode is captured in Figure 3, which shows the two drawings. The original sketch can be seen on the left of the image while the Accepted version, final publication: http://oss.sagepub.com/cgi/content/abstract/28/5/689 
updated version is on the right. In this drawing, the orientation of the depicted sports field has changed, apparently due to its aspect in relation to the north-south axis. This design development is largely based on practical decisions about the usefulness of the pitch as a sports facility (access, position in relation to the sun...). However, it is not just the aspect of the sports ground which has changed. In the newer drawing, the path (an arc running upwards from left in the image) has changed from a continuous curve shape to a more wavy form. In regard to the curve, Taylor explains, 'I bent the path so that it blends more'.

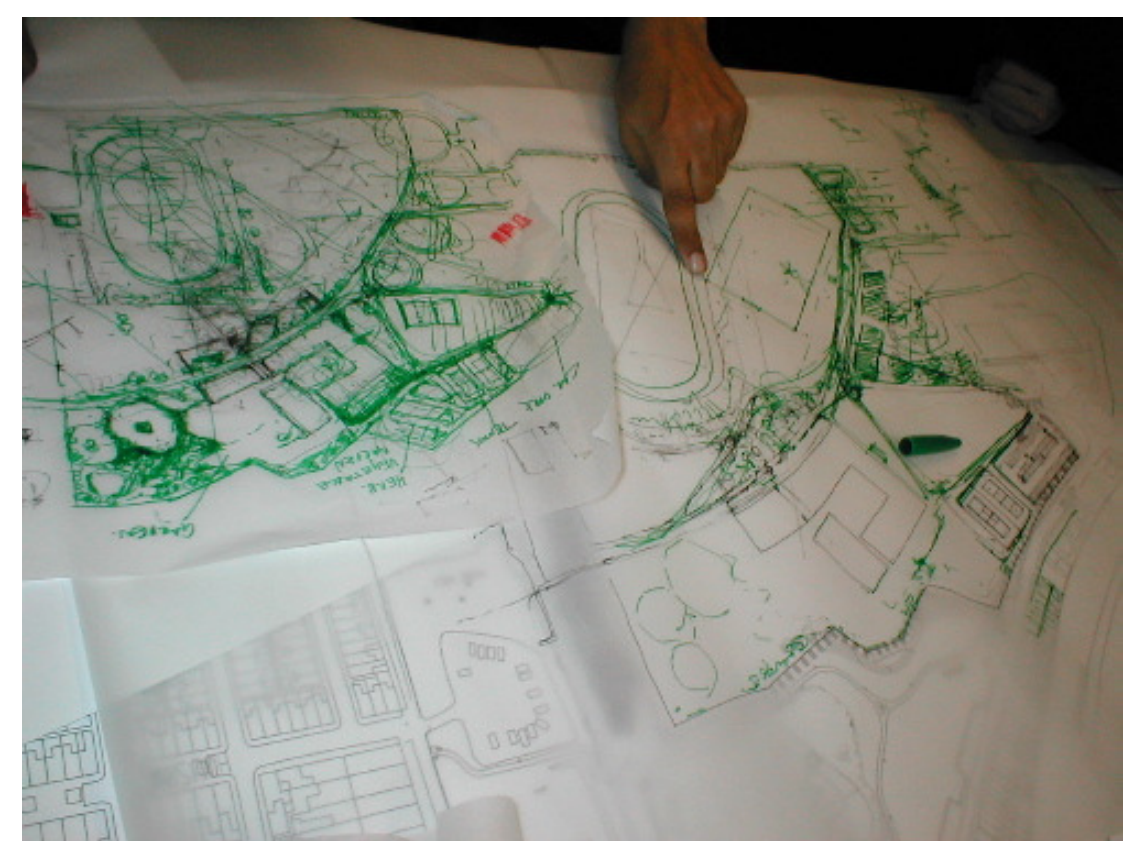

Figure 3. The original sketch, left, and a more developed version to its right.

Using the term 'blend' is revealing here, as it appears that Taylor tried to work towards a more harmonious integration between the areas on either side of the path, which may have served more as a barrier or dividing line in the original shape of an unbent arc. In the figure, Taylor's finger points to the bowed section of the path. His 
tracing and retracing of the bowed section of the path can be seen to take the form of an inquiry or even conversation, with the representation. In this 'conversation', he seemingly 'proposes' a line and then assesses its relative impact on the design. In response he then traces and retraces lines on either side of it until the design feels 'right' - a judgement on the position and shape of the path that is grounded in aesthetic knowledge.

In the observed instances, the activities of designers are understood not as rationally managed and plan-able stages nor as a sequential problem solving process, but as a kind of inquiry or even 'productive inquiry' (Cook and Brown 1999) in the form of improvised engagement with an emerging design. This dialogical engagement with materials, especially visual representations, is described by Johnny:

What we're doing is putting down the mark, putting down the pen, looking back and observing. And you then change the nature of the order of that space, and you'll see the effect. And you then try to understand the effect. And each time there's a re-iteration of that process, you're building up something. Sometimes in a negative way, so you start again, you re-sketch.

Reflexivity here is in the world. It unfolds in the interactive and dialogical exchange between a shifting work context and the practitioner. Aesthetic reflexivity thus resembles a form of knowing as productive inquiry, mediated by aesthetic knowledge.

\section{Aesthetic knowledge: understanding the 'feel' of the site and representing it}

At the team meeting, the experiential side of aesthetic knowledge is observed in discussions of the 'feel' of the site and the landscape, the application of professional judgement and the corresponding sensitivities that such judgement requires. Johnny, Peter, Taylor, Emily and James are exchanging views on how the Accepted version, final publication: http://oss.sagepub.com/cgi/content/abstract/28/5/689 
space should be experienced by the envisioned end-users. The essence of the subject is 'aesthetic'. It is understood not so much conceptually as intuitively, in ever extending and more nuanced sensitivities and competencies.

During the follow-up focus group discussion, the phrase 'the feel of the site' was offered back to the practitioners for further explanation and discussion. Looking at images of project drawings, Peter stated:

There's definitely a kind of feel for what you're looking at here as one layer of how you're judging it. And the feel is just something to do with how the geometries, how the shapes, the curves - is the composition of it sitting nicely? It must come through having seen lots and lots of these things. There's a sense of a kind of rightness of fit.

Peter describes a form of professional judgement based on cultivated sensitivity for and embodied experience of relations between 'geometries', 'shapes' and 'curves'. These relations are aesthetic, rather than narrowly numeric or otherwise simply codifiable. The competence to make such professional judgements is rooted in experiential forms of aesthetic knowledge (see Table 1). In turn, such knowledge and competency is based on learning. Peter notes how, 'It must come through having seen lots and lots of these things'.

It is to this knowledge and corresponding sensitivities and competencies that Peter seems to refer in the meeting, when urging the team to 'make sure that the hardline can convey what the hand-drawing does'. This interaction revolved around a hand-drawn sketch and a hard-line CAD drawing of a site plan, as shown in Figure 4. The hand-drawing, showing the proposed college development and a sports field separated by a curvilinear path, is heavily marked up. As an artefact, it embodies layer upon layer of inscription, containing a rich texture of information as well as a degree of ambiguity as to the precision of this information. To its right in Figure 4, the much Accepted version, final publication: http://oss.sagepub.com/cgi/content/abstract/28/5/689 
neater hard-line drawing resembles an attempt to translate the sketch into a computer drawing. It is less densely inscribed and more exact.

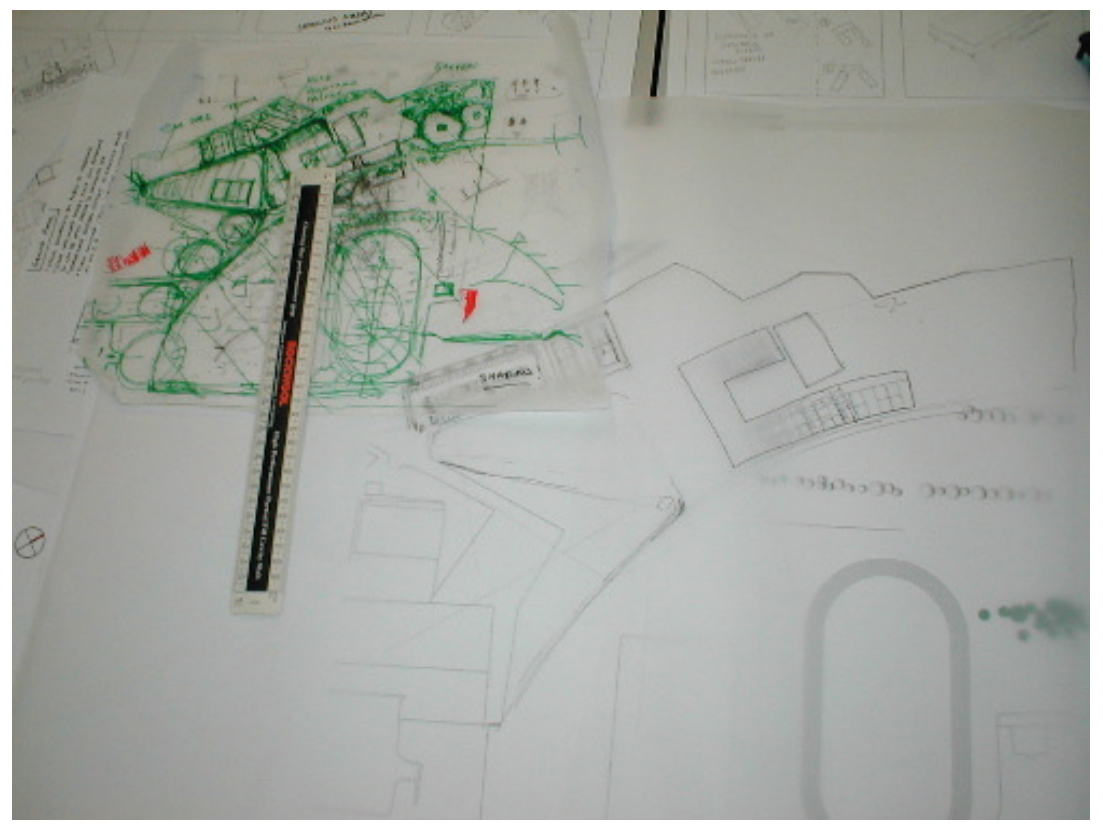

Figure 4. Sketch and hard-line drawing printed from CAD software next to each other. The two representations are at different scales.

Johnny described the relation between a hand-drawn sketch and a detailed computer drawing.

The interesting process, I think, between the sketch and the computer drawing is in a sketch you can exaggerate geometry. You can pull it outside of its natural order, to establish new orders. For instance you may want this building to be geometrically related to the running track. And when you sketch, you'll do that. But when you build it up correctly, and I mean correctly 'mathematically correctly' [...] on your hard-drawing, it isn't anymore. So you lose that.

This suggests that the necessary ambiguity of a hand-drawn sketch can allow compositional elements to develop relationships. While this type of emergence of Accepted version, final publication: http://oss.sagepub.com/cgi/content/abstract/28/5/689 
compositional elements is a common feature of architectural practice it is particularly salient within a practice such as Edward Cullinan Architects, which emphasises the asymmetry and balance of particular conditions and particular situations. The sketch contains ambiguous and implied relations between shapes and spaces in its composition. The challenge for designers is to see, discern or sense these relationships and translate them into a hard-line visual expression. This challenge demands distinct forms of aesthetic knowledge: the feeling for elements in the composition and their interrelation, and the design literacy and representational competence to translate ambiguous relations into a kind of visual representation (CAD drawing) that demands more accurate codification.

In his commentary on the imperative to "make sure that the hard-line can convey what the hand-drawing does', Peter invokes the experiential dimension of aesthetic knowledge. He explains:

Certain things come out of these types of drawings. Where you get intensities of colouring because it's been highlighted as important and people have drawn it several times, or something like that. Through that you get a kind of texture or feeling looking at that drawing of something more than just 'well, there's a line here'. Which is what is on the hard-line drawing besides it. And somehow in the translation between this and this, something's lost. The function will be the same, in that this is a building and this some kind of boundary or something around it. But the actual things that you can start to read into this, which are suggestions of surface texture or a sense of space or tightness or whatever, that start to be suggested by this drawing, really very often are lost into this [emphasis added].

In this account, the hand-drawing communicates a form of aesthetic excess. It expresses something more than highly codified lines drawn to exact specification in a CAD package. More specifically, it provides a sense of how a space should feel and lend itself to experience. Peter describes 'a kind of texture or feeling' or 'a sense of Accepted version, final publication: http://oss.sagepub.com/cgi/content/abstract/28/5/689 
space or tightness or whatever'. Being receptive to these textures and sensations activates the experiential dimension of aesthetic knowledge, or competency (see Table 1). Successfully transposing them into another medium (a CAD representation) without losing the essence of their elusive qualities draws on the symbolic dimension, or style (see Table 1). Both dimensions are enacted by individual designers and localized design teams, yet they also develop at a shared, organizational level. Across the design practice, an understanding of how spaces should feel so as to be effective is shared and expressed in a repertoire of coherent shapes, geometries, materials and images.

Despite such collective understanding, aesthetic knowledge can be elusive or 'intangible', in Robin's words. Further, it is often more subjective than codified forms of knowledge. Johnny emphasizes the subjective character of aesthetic knowledge. He speaks of a 'set of harmonics', which can be likened to embodied criteria (Bourdieu 1992), upon which aesthetic judgement is based. These categories are described as highly personal. He states:

Everyone's different, because you've got your own separate set of harmonics. And maybe some of them are learnt and maybe some of them are innate. [...] In one interwoven series of geometries, different architects, different people, will see different things they like and wish to exploit.

Alongside this emphasis on the subjective characteristics of aesthetic knowledge, Peter emphasizes the collective and shared aspects of aesthetic knowledge.

I think it's true that there is a set of shared sensibilities. Because firstly, in any kind of design practice which has a body of work, people are going to decide that they want to go and work there, having seen the body of work. So there's going to be an empathy with the work even though there's people's own adaptation of that work. [...] In the sense of the overall view of 
how buildings have a certain way of ordering themselves, I think that that's something that most people are comfortable with. You probably get that in most practices.

Peter makes reference to aesthetic knowledge in the form of 'a set of shared sensibilities' and an 'overall view of how buildings have a certain way of ordering themselves'. In this account, aesthetic knowledge is not just subjective but intersubjective. It can be shared by actors, especially in communities of practice (Lave and Wenger 1991), and operate as a selection mechanism for attracting new members to the firm. Thus aesthetic knowledge becomes seen as a form of knowledge that is jointly held and enacted by members of professional communities, organizations and networks.

Aesthetic knowledge is shared and consolidated through joint discussion of design in meetings such as the one observed on the competition project. As Ted becomes less involved in the day to day running of the project these mechanisms for sharing and developing aesthetic knowledge become more important. At an organizational level, routines such as practice-wide design reviews were implemented to support the development and accumulation of aesthetic knowledge. All members of the practice are invited to such reviews, not just those working on specific projects. Alongside shared working on projects and mentoring of newer staff, such reviews serve to consolidate and diffuse aesthetic knowledge at the organizational level.

\section{Discussion: Aesthetic knowledge and knowing in organizations}

In this paper we make links between the lived experience of members of Edward Cullinan Architects and theoretical understanding of aesthetic knowledge and knowing in organizations shown in Table 1. The vignettes of practice that we observed show how aesthetic knowledge is generated by the designers working on a competition design project through their interaction with drawings; and how this takes Accepted version, final publication: http://oss.sagepub.com/cgi/content/abstract/28/5/689 
the form of an inquiry or conversation with a material context. Through such interaction, around the particularities of sites and their related geometries, shapes and curves, the architectural practice develops and renews its aesthetic knowledge. Newer members of the practice, such as Taylor and Emily, face the challenge of learning the aesthetic knowledge of the practice, while opening it up to question, so as to revitalize that knowledge in the context of their work on contemporary and future projects.

The data shows how the architects draw on both the symbolic and experiential dimensions of aesthetic knowledge, as style and competency; and how they enact the corresponding modes of aesthetic reflexivity, as reflection and practice. It gives a sense of the dynamics surrounding aesthetic developments in an organization. The process of learning in architectural education may start with the individual development of style, then a reflection on that style, with practice leading to competency. Our observations suggest that for organizations the processes of collective aesthetic learning may instead emphasize movements from competency through its enactment in practice to further reflection and further development of the style. This discussion of process is more speculative. While we cannot be precise about the nature of the links between the categories in Table 1 from our data-set, the data clearly show the use of aesthetic knowledge and knowing as style and competency and as reflection and practice.

Our case study has implications for organizing, particularly in relation to encouraging, building up and managing aesthetic knowledge within organizations. The lessons that can be learnt from Edward Cullinan Architects include the important role played by the shared aesthetic knowledge base and the way in which individuals subscribe to this and make their own aesthetic judgements in relation to it through their practice in day-to-day work. From a strategy perspective, this is important as Accepted version, final publication: http://oss.sagepub.com/cgi/content/abstract/28/5/689 
aesthetic knowledge can be described as constituting a 'dynamic capability' of more and more organizations whose competitive advantage is grounded precisely in the kinds of skills we describe. Aesthetic reflexivity points to the practices, habits, routines and learning mechanisms that sustain and develop that capability. Our analysis extends understandings in the existing literatures to suggests that aesthetic knowledge plays an important part in organizational practice; not only as the symbolic context for work, but as an integral part of the work that people do. It suggests that aesthetic reflexivity is experienced as part of practice as well as a 'time out' from practice. This has wider implications for our understanding of knowledge within organizations.

Knowledge has sometimes been treated as objective, transferable and stable. From this perspective, the challenge for managers becomes seen as the efficient reification of knowledge. Work in the area of knowledge management, for example, concentrates on the best ways to capture, objectify and manage knowledge especially through information systems. However, such a perspective on knowledge is increasingly being challenged by work that considers knowledge as a situated accomplishment, dependent on the social context in which it appears (Gherardi 2000; Orlikowski 2002). Rather than an object to be manipulated, knowledge appears in shifting and contingent contexts where it is emergent, intersubjectively negotiated and continuously in flux (Amin and Cohendet 2004).

The findings of our study support this latter conceptualisation of knowledge. They demonstrate that aesthetic knowledge and knowing goes beyond words: including both symbolic and experiential forms. As we showed in our analysis, aesthetic reflexivity opens up a conceptual space in which to explain the mechanisms through which knowledge begins to emerge in interaction with materials and other Accepted version, final publication: http://oss.sagepub.com/cgi/content/abstract/28/5/689 
actors. Thus our broader view of aesthetic knowledge and reflexivity has an important contribution to make to ongoing debates, for example in work on organizational knowing (Nicolini et al. 2003), creativity in organizations and the creative industries (Lampel et al. 2000; Jones et al. 2005) interactions between practitioners and objects (Engeström and Blackler 2005) and wider practice-based research.

While our study has explored the context of architectural design, such knowledge and knowing is important in other organizational contexts such as scientific laboratories, retail outlets, operating theatres, football clubs, airline cabins and orchestras. In the collective practices of a football team, for example, the symbolic dimension of aesthetic knowledge and knowing is observed in the characteristic style of play or the way that games from a particular time and place become recorded and made available for reflection. The experiential dimension is observed as the team plays: in the way that players make judgements that affect their performance, based on what they hear, see and feel. Once they are analytically distinguished and brought to our attention, forms of aesthetic knowledge and reflexivity appear pervasively in a wide variety of organizational contexts. This points to a new research agenda.

\section{References}

Amin, Ash, and Patrick Cohendet

2004 Architectures of knowledge. Oxford: Oxford University Press.

Antonacopoulou, Elena, and Haridimos Tsoukas

2002 'Time and reflexivity in organization studies: an introduction'. Organization Studies 23/6: 857-862.

Barthes, Roland

1977 Image, music, text. London: Fontana Press.

Accepted version, final publication: http://oss.sagepub.com/cgi/content/abstract/28/5/689 
Beck, Ulrich

1992 Risk society. London: Sage.

Bourdieu, Pierre

1992 'Commentary on the commentaries'. Contemporary Sociology 21/2: 158-161.

Cullinan, Ted

1995 [1986] 'Where does my baggage come from' republished in Edward Cullinan

Architects. Kenneth Powell. London: Academy Editions. pp. 142-151.

Cook, Scott D.N., and John Seely Brown

1999 'Bridging epistemologies: the generative dance between organizational knowledge and organizational knowing'. Organization Science 10/4: 381-400.

Cook, Scott, and Dvora Yanow

1993 'Culture and organizational learning'. Journal of Management Inquiry 2/4: 373-390.

Dean, James W. Junior, Edward Ottensmeyer and Rafael Ramirez

1997 'An aesthetic perspective on organizations'. Creating tomorrow's organizations, Cary L. Cooper and Susan E. Jackson (eds). New York: Wiley.

Denzin, Norman K., and Yvonna S. Lincoln, editors

1994 Handbook of qualitative research. London: Sage.

Dreyfus, Hubert L., and Stuart E. Dreyfus

2005 'Expertise in real world contexts'. Organization Studies 26/5: 779-792.

Engeström, Yrjö, and Frank Blackler, editors

2005 'Special issue: On the life of the object'. Organization 12/3.

Ewenstein, Boris

2004 'Post-subculture and reflexivity: cultural learning in London and Berlin'. $\mathrm{PhD}$ thesis, Goldsmiths College, University of London, UK.

Finch, Paul

2005 'Beginnings Ends Middles Beginnings'. Ends, middles, beginnings: Edward

Cullinan Architects. Jonathan Hale. London: Blackdog Publishing.

Gagliardi, Pasquale

1996 'Exploring the aesthetic side of organizational life'. Handbook of organization studies. Stuart Clegg, Cynthia Hardy and Walter Nord (eds). London: Sage.

Geertz, Clifford

1973 The interpretation of cultures. London: Fontana Press.

Gendlin, Eugene T.

1992 Giving the body its due. Albany: State University of New York Press.

Accepted version, final publication: http://oss.sagepub.com/cgi/content/abstract/28/5/689 
Gherardi, Silvia

1999 'Learning as problem-driven or learning in the face of mystery?'

Organization Studies 20/1: 101-124.

Gherardi, Silvia

2000 'Practice-based theorizing on learning and knowing in organizations'. Organization 7/2: 211-223.

Giddens, Anthony

1991 Modernity and self-identity. Cambridge: Polity Press.

Glaser, Barney G., and Anselm L. Strauss

1967 The Discovery of Grounded Theory. London: Weidenfeld and Nicolson.

Hancock, Philip, and Melissa Tyler

2000 'The Look of Love: Gender and the organization of aesthetics'. Body and Organization, John Hassard, Ruth Holliday and Hugh Willmott (eds). London: Sage.

Jones, Candace, Anand Narasimhan, and Josè Luis Alvarez

2005 'Guest editors' introduction: Manufactured authenticities and creative voice in cultural industries'. Journal of Management Studies 42/5: 893-899.

Lampel, Joseph, Theresa Lant, and Jamal Shamsie

2000 'Balancing act: Learning from organizing practices in cultural industries'. Organization Science Special Issue: Cultural Industries: Learning from Evolving Organizational Practices 11/3: 263-269.

Lash, Scott, and John Urry

1994 Economies of signs and space. London: Sage.

Lave, Jean, and Ettiene Wenger

1991 Situated learning: legitimate peripheral participation. Cambridge: Cambridge University Press.

Linstead, Stephen, and Heather Höpfl, editors

2000 The aesthetics of organization. London: Sage.

Mead, George Herbert

1934 Mind, self and society. Chicago: University of Chicago Press.

Nickson, Dennis, Chris Warhurst, Anne Witz, and Anne Marie Cullen

2001 'The importance of being aesthetic: work, employment and service organization'. Customer service: empowerment and entrapment. Andrew Sturdy, Irena Grugulis and Hugh Willmott (eds). Basingstoke and New York: Palgrave.

Nicolini, Davide, Silvia Gherardi, and Dvora Yanow editors 
2003 Knowing in organizations: a practice-based approach. Armonk, New York: ME Sharpe.

Orlikowski, Wanda J.

2002 'Knowing in practice: enacting a collective capability in distributed organizing'. Organization Science 13/3: 249-273.

Powell, Kenneth

1995 Edward Cullinan Architects. London: Academy Editions.

RIBA (Royal Institute of British Architects)

1984 Edward Cullinan Architects. London: RIBA Publications Limited.

Rosen, Michael

1988 'You asked for it: Christmas at the bosses' expense'. Journal of Management Studies 25/5: 463-480.

Saussure, Ferdinand, de

1983 Course in general linguistics. London: Duckworth.

Schön, Donald A.

1983 The reflective practitioner: how professionals think in action. New York: Basic Books.

Schön, Donald A.

1985 The design studio: an exploration of its traditions and potentials. London: RIBA Publications.

Schutz, Alfred

1967 The phenomenology of the social world. Evanston: Northwestern University Press.

Silverman, David

2000 Doing qualitative research: a practical handbook. London: Sage.

Strati, Antonio

1990 'Aesthetics and organizational skill'. Organizational symbolism. Barry A. Turner (ed). Berlin: De Gruyter.

Strati, Antonio

1996 'Organizations viewed through the lens of aesthetics'. Organization 3/2: 209218.

Strati, Antonio

1998 'Organizational symbolism as a social construction: a perspective from the sociology of knowledge'. Human Relations 51/11: 1379-1402.

Strati, Antonio

1999 Organization and aesthetics. London: Sage. 
Strati, Antonio

2000 Theory and method in organization studies. London: Sage.

Thompson, Paul, Chris Warhurst and George Callaghan

2001 'Ignorant theory and knowledgeable workers: interrogating the connections between knowledge, skills and services'. Journal of Management Studies 38/7: 923-942.

Van Maanen, John

1975 'Police socialization: A longitudinal examination of job attitudes in an urban police department'. Administrative Science Quarterly 20/2: 207-228.

Van Maanen, John

1979 'The fact of fiction in organizational ethnography'. Administrative Science Quarterly 24/4: 539-550.

Whitfield, T.W. Allan

2005 'Aesthetics as pre-linguistic knowledge: A psychological perspective'. Design Issues 21: 3-17.

Witz, Anne, Chris Warhurst and Dennis Nickson

2003 'The labour of aesthetics and the aesthetics of organization'. Organization 10: 33-54.

Yanow, Dvora, and Haridimos Tsoukas

2005 'Reflecting in / on practice'. Paper presented at the $21^{\text {st }}$ EGOS Colloquium: Unlocking Organizations, Berlin, 30 June-2 July. 